\title{
Analysis of Google Trends to monitor new psychoactive substance. Is there an added value?
}

\author{
Frana-Katica Batistic ${ }^{\mathrm{a}}$, Damien Rhumorbarbe ${ }^{\mathrm{b}}$, Elodie Lefrancois ${ }^{\mathrm{b}}$, Justice Tettey ${ }^{\mathrm{c}}$, \\ Martin Raithelhuber ${ }^{\mathrm{c}}$, Quentin Rossy ${ }^{\mathrm{b}}$, Marie Morelato ${ }^{\mathrm{a}, *}$ \\ ${ }^{a}$ Centre for Forensic Science, School of Mathematical and Physical Sciences, University of Technology Sydney, Australia \\ ${ }^{\mathrm{b}}$ Ecole des Sciences Criminelles, Faculty of Law, Criminal Justice and Public Administration, University of Lausanne, Switzerland \\ ${ }^{\mathrm{c}}$ Laboratory and Scientific Section, Division for Policy Analysis and Public Affairs, United Nations Office on Drugs and Crime, Vienna International Centre, Vienna, \\ Austria
}

\section{A R T I C L E I N F O}

\section{Article history:}

Received 20 May 2021

Received in revised form 16 July 2021

Accepted 18 July 2021

Available online 21 July 2021

\section{Keywords:}

Discussion forum

Early warning system

Threat detection

Web

Internet

\begin{abstract}
A B S T R A C T
The past decade has seen an increase in the development and availability of a broad category of drugs, known as new psychoactive substances (NPS). NPS are challenging for public health authorities, therefore the two major drug monitoring bodies - the European Monitoring Centre for Drugs and Drug Addiction (EMCDDA) and the United Nations Office on Drugs and Crime (UNODC) - have implemented the EU Early Warning System (EWS) and Early Warning Advisory (EWA), respectively. While these monitoring systems are informative, it is difficult to keep up with the constant and rapid developmental rate of NPS. The EMCDDA has recognised the need for an alternative and technologically derived early warning system. The aim of this research is to determine whether Google Trends and drug discussion forum data can be used to complement early warning systems for NPS.

Forty-eight substances were used in this study and classed into groups based on their chemical structure, following the UNODC classification system. Google Trends data (time range: 2004-2019) and drug forum data (time range: 2003-2018) were extracted for each substance and visual trend profiles were created for class groups as well as individual substances. Analysis was conducted to determine when a substance first appeared on Google Trends and a drug discussion forum as well as their trends over time. This date of first appearance was then compared to the date the substance was first reported to UNODC.

Of the three data sources utilised, substances were most likely to appear on Google Trends first. Amongst the different classes of NPS, discernible trends ('block', 'successive', and 'generational' trends) were observed. These trends reflect the evolution of the manufacture of substances or generations of substances that has been observed in the literature. For example, in the synthetic cannabinoids' category, a generational trend is observed that corresponds to the different generations of synthetic cannabinoids. When comparing Google Trends and Drugs-Forum directly, the order of appearance and duration of presence for substances aligns accurately for most classes.

Google Trends showed the emergence, persistence, or transient nature of substances, which could direct the focus of law enforcement, health organisation and laboratory resources towards a limited number of substances. When one considers the reliance of individual information seeking on the Web as well as the prominence of NPS on the Web, it becomes clear that Google Trends and drug discussion forums could be used as a complement to current early warning systems.
\end{abstract}

(c) 2021 Elsevier B.V. All rights reserved.

\footnotetext{
* Correspondence to: Centre for Forensic Science, University of Technology Sydney, PO Box 123, Broadway, 2007, Australia.

E-mail addresses: Franabatistic@gmail.com (F.-K. Batistic), Damien.Rhumorbarbe@unil.ch (D. Rhumorbarbe),

Elodie.Lefrancois@unil.ch (E. Lefrancois), Justice.Tettey@un.org (J. Tettey), Martin.Raithelhuber@un.org (M. Raithelhuber), Quentin.Rossy@unil.ch (Q. Rossy), Marie.Morelato@uts.edu.au (M. Morelato).
}

\section{Introduction}

The past decade has seen the proliferation of a broad category of drugs, known as new psychoactive substances (NPS) [1-6]. The chemical structure of NPS varies greatly and is based not only on compounds extracted from patent literature but also analogues of illicit drugs or prescribed medications as well as new substances of 
abuse [7]. Some substances and their effects are well known while for others, little is known about their effects and toxicity. There has been an increase in the rate of reported adverse events associated with several NPS, including mass infections, psychosis, seizures, acute poisonings, and overdoses [3,4,8,9]. The dynamic nature of the market and the paucity of information on toxicology, contraindications, physical and mental side effects, and treatments for a large number of NPS means that there is a continual demand for research into understanding the pharmacodynamics and pharmacokinetics of these substances [1,4,8,10-15]. Nevertheless, many NPS are able to, and are, causing severe harm to users [4]. As the legal status of NPS varies between countries, only a few substances have been included in the International Drug Conventions, which further enhances the ease of international trafficking $[4,5,8,13,14]$.

In response to the increase in NPS, the European Monitoring Centre for Drugs and Drug Addiction (EMCDDA) and the United Nations Office on Drugs and Crime (UNODC), implemented the EU Early Warning System (EWS) and Early Warning Advisory (EWA), respectively $[4,9,16]$. For example, in the EWS, once the presence of an NPS is reported to an agency, monitoring of the substance can begin. Monitoring involves identifying any harms related to the NPS and determining the need to perform a risk assessment on a new substance $[3,4,9,17,18]$. While these monitoring tools are informative, they are unable to keep up with the constant and rapid developmental rate and their proactivity is limited $[3,5,9,10,15]$. Additionally, it is very difficult to detect all substances and there is no analytical method to cover all NPS; some may not even reach the risk assessment stage. Moreover, in order for the risk assessment to lead to control of a substance, there must be clear evidence of psychoactivity, likelihood of dependence, health and social impact [14]. As such, the EMCDDA has recognised the need for a complementary early warning system with a focus on technologically-derived insights that are both sensitive and flexible [3,9].

Given the large number of NPS and the limited understanding of their effects and markets, monitoring systems that can effectively collect and analyse information on their use or interest in a timely fashion are important and were explored in this research. As the internet is an important resource for drug-related information, it makes sense to evaluate its potential to feed early warning systems $[19,20]$. Online activities in public settings leave traces upon which monitoring methodologies may rely. For instance, historical data from online search or online discussions in forums might be used to follow trends of popularity $[20,21]$.

Minimal work has been conducted in regard to monitoring the presence and evolution of substances via drug forum discussions. One key study in this area, dubbed 'The Psychonaut Web Mapping Project', involved the development and use of an integrated web mapping system in order to identify emerging trends in NPS over a two-year period $[11,12]$. This project found that in regard to drug availability and use, forums provided unique information unattainable through other research methods (such as surveys). The web mapping system was able to record details on over 400 compounds before they were able to reach a wider audience or appear in scientific literature and indicated that the monitoring system should not only be continued but expanded to cover a wider consumer perspective. In 2019, Rhumorbarbe et al. [20] echoed these findings, where a major drug discussion forum was systematically monitored in order to map the discussion intensity of different NPS and relate this to their popularity over time. Not only was an evolution of substances classes and evolution of individual substances within classes identified, a number of NPS were first present on the forum before or at the same time as their EWS notification. These findings complemented the notion that harnessing and analysing the information available on drug forums would be of great assistance to early warning systems.
Regardless of the intentions of the work on extraction of drug forum information, the overarching consensus indicates that there is a wealth of information available on these forums and this is a crucial resource that should be harnessed.

Alternatively, Google Trends is a great source of public data for forecasting global consumption indirectly, as it has been shown that consumers will turn to search engines to collect information on items they are interested in purchasing [22]. Studies using Google Trends have found that the tool gives clear insight into consumer interest, high correlative data as predictor of future activity, and search data is large, constantly available, and in almost realtime [23-26].

Despite this, minimal work has been conducted into the utilisation of Google Trends data in the context of drugs, with some studies focusing on the identification of NPS fatalities [27] and linking search traffic to media publications [18,28]. The most comprehensive work on Google Trends data has been conducted by Al-Imam \& Abdul Majeed [23,29-32]. Employing basic keywords in the NPS vocabulary, their works have sought to identify the most popular categories of NPS, conduct geo-mapping of surface-web users, and assess the power of cryptomarkets, based on the retrieval and analysis of Google Trends data [23,29-31]. Each of their studies have identified a clear analogy between the data available on Google Trends and patterns identified on the Dark web. Additionally, their related work into Google Trends has found that it appears to be an important tool for integration into early warning systems [23], which in this case should be considered in the context of the evergrowing arena of NPS. A 2016 study by Gamma et al. which compared Google search interest with related criminal offences for methamphetamine in three countries, found a correlation between this online search activity and related criminal activity and as such could possibly be used as an indicator for such drug-related crimes [26].

The aim of this research was to determine whether Google Trends could be used in conjunction with drug forum data as a new or complementary early warning system for NPS monitoring, alongside the Early Warning System and Early Warning Advisory. Thus, Google Trends data for forty-eight (48) distinct NPS were analysed and compared to both the observed activity on a popular drug forum and the first reported date to UNODC.

\section{Method}

\subsection{Targeted Substances}

A total of forty-eight distinct NPS were selected as target substances (see Table 1). This selection was based on the most common NPS reported to the UNODC Early Warning Advisory on NPS between 2009 and 2015 and covered the main classes of NPS of the UNODC chemical classification system (i.e. structural similarity to a parent compound) [33]. Even if some of the substances included are not currently classed as NPS in certain countries due to legislative differences, there are a set of those most commonly reported to the UNODC Early Warning Advisory and were used in previous research [20]. The UNODC uses both a chemical and an effect-based classification [34]. Although it may be argued that consumers use drugs for a specific desired effect and thus an effect-based classification would be more appropriate, some substances may have more than one effect. For example, substances within the stimulant effect group affect the levels and actions of the monoamine neurotransmitters dopamine, norepinephrine, and serotonin thus sometimes leading to hallucinatory effects in addition to the predominant psychostimulant effects. Consequently, this study focuses on the chemical classifications rather than the effect classification to simplify the analysis. 
Table 1

A complete list of the forty-eight NPS targeted in this work. They are separated by UNODC chemical class distinction and a note of the year first reported to the UNODC.

\begin{tabular}{lr}
\hline \multicolumn{2}{l}{ Phencyclidine-type substances } \\
MXE & 2010 \\
4-MEO-PCP & 2011 \\
3-MEO-PCP & 2010 \\
Aminoindanes & \\
MDAI & 2010 \\
2-AI & 2010 \\
5-IAI & 2011
\end{tabular}

\begin{tabular}{|c|c|}
\hline \multicolumn{2}{|c|}{ Plant-based substances } \\
\hline Khat & 2009 \\
\hline Kratom & 2009 \\
\hline Salvia divinorum & 2009 \\
\hline \multicolumn{2}{|c|}{ Synthetic cathinones } \\
\hline a-PVP & 2010 \\
\hline MDPV & 2009 \\
\hline Mephedrone & 2009 \\
\hline n-ethyl-pentylone & 2011 \\
\hline 3-FMC & 2009 \\
\hline \multicolumn{2}{|l|}{ Piperazines } \\
\hline BZP & 2009 \\
\hline MBZP & 2009 \\
\hline $\mathrm{mCPP}$ & 2009 \\
\hline PFPP & 2009 \\
\hline TFMPP & 2009 \\
\hline \multicolumn{2}{|l|}{ Phenethylamines } \\
\hline PMMA & 2009 \\
\hline 25C-NBOMe & 2010 \\
\hline 25I-NBOMe & 2012 \\
\hline $2 C-E$ & 2009 \\
\hline 2C-I & 2009 \\
\hline 2C-T-2 & 2009 \\
\hline 2C-T-7 & 2009 \\
\hline 4-FA & 2009 \\
\hline $5-\mathrm{APB}$ & 2010 \\
\hline 6-APB & 2010 \\
\hline 2-CB-FLY & 2009 \\
\hline 5 -IT & 2012 \\
\hline 4,4'-DMAR & 2013 \\
\hline
\end{tabular}

\subsection{Data collection}

\subsubsection{Google Trends}

Google Trends is a free and publicly accessible service created by Google ${ }^{\circledR}$ which allows users to view the frequency of searches for a term, a string of multiple terms, or a phrase, dating back to January 1st, 2004 [35-37]. On March 16th, 2019, a Google Trends search was conducted for each of the forty-eight distinct NPS terms outlined in Table 1. For each term, the following parameters were specified: (1) geographical location: Worldwide, (2), time range: 2004 -2019 (i.e. 01/01/2004 - 16/03/2019), (3) category: All categories. Data (i.e. search volume) was collected through the exportation tool available on the website. The Google Trends output is an index of the relative search volume; the data is scaled according to the average search quantity for the term (over the selected time period and geographical location), and normalised to provide a relative volume where maximum search interest is '100' and minimum search interest is '0' [22,35-37].

\subsubsection{Drugs-Forum}

Drugs-Forum.com is a major online discussion forum. With over 250,000 registered members, it covers general discussion upon drugs, with a focus on harm reduction [20]. Internal rules states that "By submitting content, you agree that it is publicized on this site network". ${ }^{1}$ From an ethical perspective, forums are considered as secondary data created by others, but made available to the researcher. Even though the content of the discussions may be considered as public data, several measures were taken to protect user privacy. Individual quotes were avoided as they might be deanonymized through online searches. Only aggregated results were presented. Results did not contain sensitive personal information and did not target specific people through virtual identities $[20,38]$. Moreover, whilst the website contains a number of sub-sections, only one entitled 'Drug Information \& Harm Reduction' was used for this study.

A Python-coded system (Python 2.7 and BeautifulSoup 4.4.0) was designed to crawl the section's data and scrape the needed information from 2003 to 2018 [20]. The system works in two stages: (1) identification of discussion threads related to selected substances and (2) extraction of the number of replies and views and of the time of all subsequent discussion threads. The number of replies normalised over the total number of replies for each substance during the period investigated was used as an indicator of discussion intensity for each substance [20]. In order to obtain the same scale as the Google Trends data, the normalised replies were provided as a percentage (from 0 to 100).

\subsubsection{UNODC NPS Reports}

The UNODC has recorded reports of the presence of NPS since the beginning of 2009 via the Global Synthetics Monitoring: Analyses, Reporting and Trends (SMART) Programme, but as of 2013 this is reported by the Early Warning Advisory on NPS (EWA) [16,39].

The presence of NPS can be reported to the EWA by a variety of sources, including government authorities, laboratories, and partner organisations [40]. When the EWA is informed of the presence of a previously unreported NPS, the year of first reporting is recorded. Year rather than date/month is recorded to ensure consistency with official data collection instruments, such as the UN Annual Report Questionnaire ,2 which collects drug-related information using an annual/biannual cycle. Table 1 outlines the year each of the targeted substances was reported to the UNODC (via either SMART or EWA).

\subsection{Data analysis}

Data from Google Trends and Drugs-Forum.com were combined and the start and end dates of appearance of each NPS were recorded. Google Trends start dates were identified as starting on the first date a sufficient number of searches were conducted to produce a non-zero result in the dataset. Drugs-Forum.com start dates were identified as starting at the creation date of the first thread discussing that substance.

Changes in the intensity of discussion (used as a proxy for popularity for each substance on both Google Trends and DrugsForum) were investigated and compared over time.

Trends for each substance can be classified in four groups: upward trends, chronic trends, downward trends, and temporary increase [21]. However, when it comes to analysing trends within a class containing multiple substances, more complex patterns can be detected. The different trend types observed were classified as 'block', 'successive', and 'generational' trends:

- A block trend is observed when the popularity of substances is grouped into the same period and exhibit similar increase and decrease of popularity. This trend type might be the sign of a global interest for a family of substances.

- A successive trend is observed when popularity peaks are sequential for each substance so that when one substance begins to lose popularity, another one concentrates the attention. This trend type might be the sign of a change of interest.

- A generational trend is observed when multiple block trends are successively observed. This trend might be the sign of a change of interest for families of substances.

Finally, the start dates (year only) were then compared to the UNODC year of report. Microsoft Excel (version 1904) was used for 


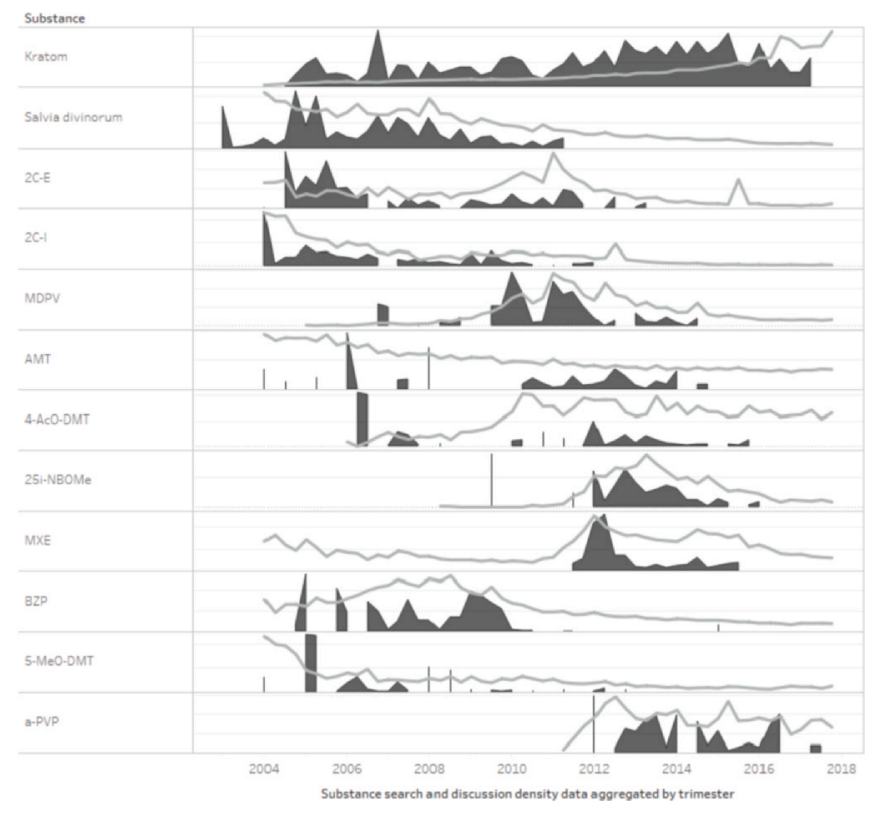

Fig. 1. Comparison of the trends between Drugs-Forum.com (black areas) and Google Trends data (grey line).

data compilation, pre-treatment and Tableau software (version 2019.1.0) was used for visualisation.

\section{Results and discussion}

\subsection{Comparison of online indicators}

The first comparison was made between Google Trends and Drugs-Forum. Six substances were only detected on Google Trends, 31 substances were detected on Google Trends first, 7 on DrugsForum first, and 4 simultaneously. For substances appearing first on Drugs-Forum, substances appeared on Google Trends within 1-54 months (median of 7 months). For substances appearing first on Google Trends, substance appeared on Drugs-Forum within 1-88 months (median of 10 months).

For substances with enough Drugs-Forum data to detect trends (more than 20 distinct temporal data points derived from at least 1\% of the total number of replies across the threads related to a substance), similar trends were observed (see Fig. 1). In some cases, trends vary in regard to the intensity of the discussion, but more often than not, the period of most interest are the same in both data sources. Google Trends gives a more continuous dataset. Indeed, some substances might not be discussed on forums for months.

\subsection{Comparison of the online indicators with the UNODC report year}

It is important to note that the initial dates vary for each indicator. Drugs-Forum began in 2002 and Google Trends began recording data in 2004. Only three substances appear on Drugs-Forum data prior to 2004, likely due to their longstanding presence as substances of use (e.g. Kratom and Salvia divinorum). The UNODC began recording NPS reports in 2009, leaving at least a 5 years gap when compared to the other two sources. Some substances may have been previously reported, but as there was no formal reporting and recording procedure in the UNODC for NPS prior to implementation of SMART and the EWA, these substances are reported by default in 2009 .

As such, the comparison between the three sources in Table 2 is only for 21 substances with a UNODC reporting year post-2009.
Table 2

First reporting year by UNODC compared to years of detection on Google Trends and Drugs-Forum. The year of first detection is highlighted in bold.

\begin{tabular}{lllll}
\hline & \multicolumn{2}{l}{ Year of first detection } \\
\cline { 3 - 4 } & & UNODC & $\begin{array}{l}\text { Google } \\
\text { Trends }\end{array}$ & $\begin{array}{c}\text { Drugs- } \\
\text { Forum }\end{array}$ \\
\hline Substance & & 2010 & $\mathbf{2 0 0 4}$ & 2007 \\
& 2-AI & 2010 & $\mathbf{2 0 0 9}$ & 2011 \\
& 3-MEO-PCP & 2011 & $\mathbf{2 0 0 8}$ & $\mathbf{2 0 0 8}$ \\
4-MEO-PCP & $\mathbf{2 0 1 0}$ & $\mathbf{2 0 1 0}$ & 2011 \\
5-APB & 2011 & $\mathbf{2 0 1 0}$ & $\mathbf{2 0 1 0}$ \\
5-IAI & $\mathbf{2 0 1 0}$ & $\mathbf{2 0 1 0}$ & $\mathbf{2 0 1 0}$ \\
6-APB & 2010 & $\mathbf{2 0 0 8}$ & 2010 \\
25C-NBOMe & 2012 & $\mathbf{2 0 0 8}$ & 2009 \\
25I-NBOMe & $\mathbf{2 0 1 0}$ & 2011 & 2012 \\
a-PVP & $\mathbf{2 0 1 2}$ & $\mathbf{2 0 1 2}$ & 2013 \\
AB-PINACA & $\mathbf{2 0 1 1}$ & $\mathbf{2 0 1 1}$ & $\mathbf{2 0 1 1}$ \\
AM-2233 & 2011 & $\mathbf{2 0 0 7}$ & 2012 \\
APINACA & 2010 & $\mathbf{2 0 0 4}$ & 2009 \\
MDAI & 2010 & $\mathbf{2 0 0 4}$ & 2011 \\
MXE & $\mathbf{2 0 1 1}$ & 2016 & 2016 \\
N-ethyl- & & & \\
pentylone & $\mathbf{2 0 1 3}$ & 2014 & N/A \\
4,4'-DMAR & $\mathbf{2 0 1 5}$ & $\mathbf{2 0 1 5}$ & N/A \\
5F-MDMB- & & & \\
PINACA & 2012 & $\mathbf{2 0 0 4}$ & N/A \\
5-IT & $\mathbf{2 0 1 3}$ & $\mathbf{2 0 1 3}$ & N/A \\
AB-CHMINACA & $\mathbf{2 0 1 4}$ & $\mathbf{2 0 1 4}$ & N/A \\
ADB-CHMINACA & $\mathbf{2 0 1 4}$ & N/A \\
MDMB-CHMICA & $\mathbf{2 0 1 4}$ & &
\end{tabular}

When comparing solely Google Trends and UNODC, 10 of 21 substances (48\%) appeared on Google Trends before the UNODC report year, 3 (14\%) were first reported to the UNODC, and $8(38 \%)$ appeared on Google Trends in the same year as their UNODC report. For the substances proactively detected on Google Trends, the difference in reporting year was from 1 to 8 years, with a median delay of 4 years. For substances reported by the UNODC first, the difference in reporting year was either 1 or 5 years, with a median delay of 1 year.

Fifteen substances were available across all three sources. Six were not detected on Drugs-Forum. Seven were first recorded on Google Trends, two by the UNODC, two simultaneously by Google Trends and Drugs-Forum, two simultaneously by Google Trends and the UNODC, and two by all sources. Thus, no substances were detected proactively on the forum.

\subsection{Analysis of the results of Google Trends}

To assess whether google trends is a useful indicator and measures search intensity for a substance, it was first evaluated over time and compared to the literature.

\subsubsection{Global trends}

Fig. 2 represents the global trends for all substances (histograms) and substances in each class between 2004 and March 2019.

Global search behaviours showed that the peak of interest for the selected NPS was in 2010 with all the 48 substances monitored grouped together. However, distinct patterns were visible when looking at the subset of substances grouped by class. Plant-based substances appeared to follow a chronic trend all over the period, with a tendency to increase, whereas tryptamines substances followed a reverse trend. Phenethylamines and PCP-type substances followed a block trend, which seemed inversely related to the global trend of piperazines. A successive trend seemed to link both groups. The global peak observed in 2010 and 2011 appeared to be related to synthetic cannabinoids and cathinones, as well as aminoindanes search $[41,42]$. The latter concentrated interest for a very small period, whereas the other two remained regularly searched. According to Castaneto et al. [41], the American Association of Poison 


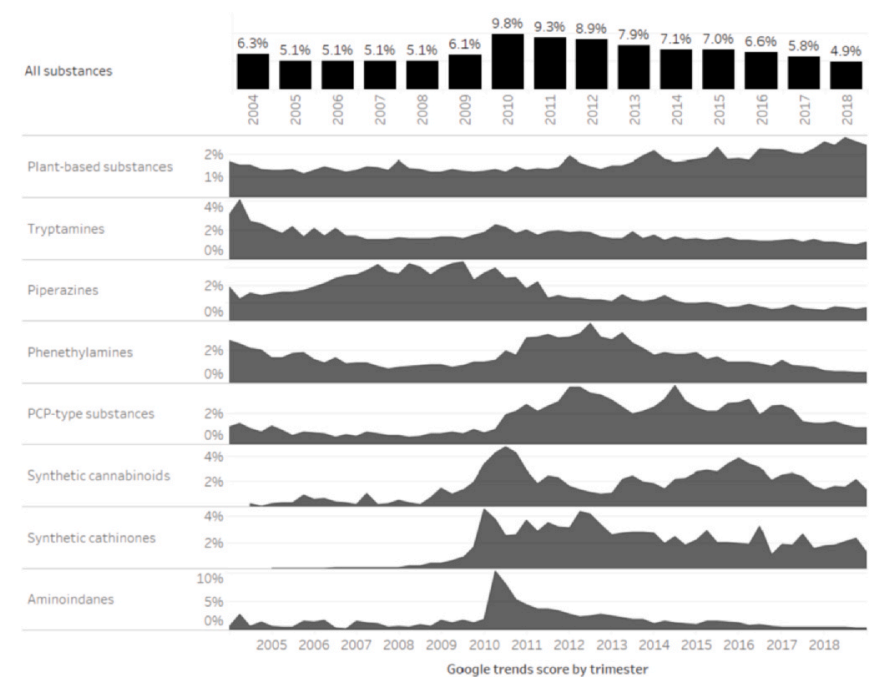

Fig. 2. Global trends represented by trimester for all substances (histogram) and for classes of substances.

Control Call Centers recorded an increase number of calls related to synthetic cannabinoids between 2010 and 2012. There was also a two-fold increase in the number of synthetic cannabinoids-related emergency department visits between 2010 and 2012 [41]. Except for plant-based substances that followed a chronic trend, a global generational trend was apparent in the search activities. However, the intensity of the search activities should not be compared between classes, since only a subset of substances were selected for the analysis. The global intensity might thus be under evaluated. To better understand the trend of each class, the trends of each substances were compared in the following sections.

\subsubsection{Plant-based substances}

Fig. 3 represents the visual trend profiles of the three plant-based substances studied in this article.

While the global trends for the class showed a chronic trend, important variations are visible depending on each individual substance. Salvia divinorum was the first substance to show a large activity profile. As its popularity dropped, both Khat and Kratom experienced a steady rise of interest. Khat seems to maintain a high volume of searches during the period of increased popularity in Kratom.

\subsubsection{Tryptamines}

Fig. 4 represents the visual trend profiles of the five tryptamines studied in this article.

Four substances (AMT, 5-MeO-DMT, 4-AcO-DipT and 5-MeODPT) had a high density of activity and then followed a downward block trend pattern, which led to the global trend observed for the class (see Fig. 2). The decline seems to have started before the increase in popularity of the 4-AcO-DMT. It should however be noted that AMT interest remains at a global high level. Whilst this sustained popularity throughout the study period could be a credit to this substance's popularity consumption-wise, it is also likely due to its name bearing similarity to popular acronyms that may have been searched for (such as Association of Massage Therapists, Australian Maths Trust, Renault AMT, and AMT Train lines). This limitation is discussed in further detail in Section 3.5.

\subsubsection{Piperazines}

Fig. 5 represents the visual trend profiles of the five piperazines studied in this article.

There was a high level of search activity for almost all substances from the beginning of 2004 until the end of 2011. A block trend is visible for all substances. The observed pattern for the class might thus be the sign of a global tendency for this group of substances. Since 2012, all substances have shown a global drop in search activity. The piperazine class is an entirely synthetically derived group of substances which were first marketed in the early 2000's [43,44]. In the literature, they were described to be some of the most popular substances of abuse. However, the scheduling to control the availability of piperazine-based party pills in 2008 in European countries resulted in a marked decrease in use of this group [43-47]. Indeed, this control may have resulted in a substantial decrease in the availability of piperazines on the market. In the Google Trends data, the drop starts in 2010. This delay in impact of substance control could be due to the reported stockpiling of piperazine pills immediately prior to the announcement of scheduling, leading to a continued search for availability of these substances or a search for information about their negative effects [48].

\subsubsection{Phenethylamines}

Fig. 6 represents the visual trend profiles of the thirteen phenethylamines studied in this article.

The phenethylamines class seemed to follow a generational trend, which explain the global pattern observed for the class (see Fig. 2). The first generation lasted from the beginning of 2004 until the beginning of 2010 and saw a sharp popularity for the $2 C$ family (2-CB-FLY, 2C-T-7, 2C-T-2, 2-CE and 2-CI). The 2C family has been available on the market since the 1990's and have been a major source of reporting in the period of 2005-2009 [49-51].

The second generation included several groups of products, the Benzofurans (5-APB and 6-APB), the N-BOMe family (25C-NBOMe and 25I-NBOMe), as well as three other substances (4-FA, 4,4'-DMAR, and 5-IT). This second wave of interest was also visible for $2 C-E$. The APB's were detected on the market around 2010-2011, and increasingly reported since 2011 with the N-BOMe's family [50-52]. The sharp rise in 5-IT around 2012 seems to be linked to a number of reported deaths around this period [53].

PMMA appeared to be the 'reference substance' of the class. Although it followed a similar pattern as generation one, its activity decreased at a much slower rate and its search volume remained

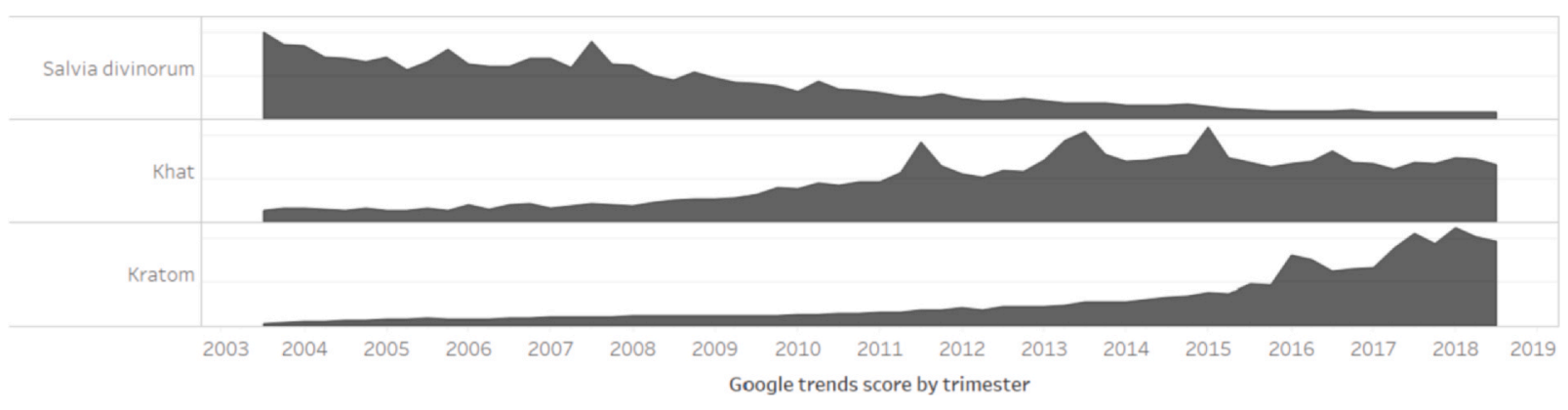

Fig. 3. Visual trend profiles of the three plant-based substances. 


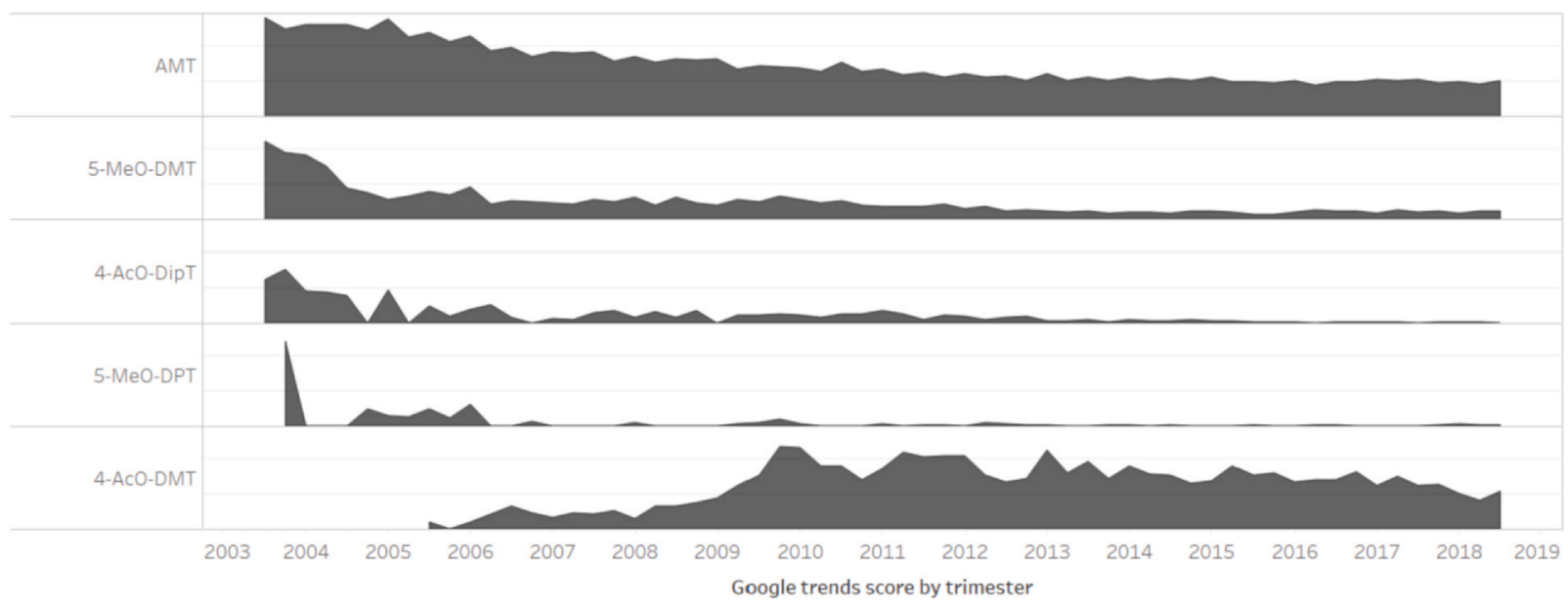

Fig. 4. Visual trend profiles of the five tryptamines.

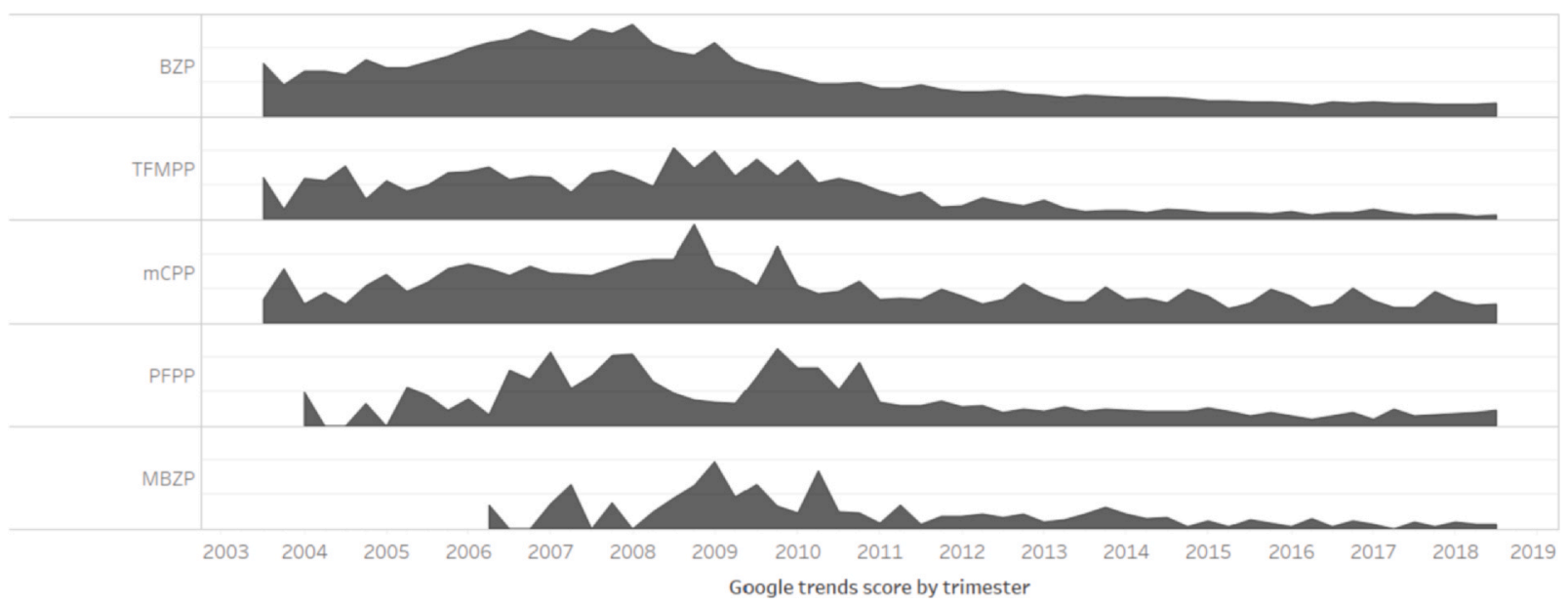

Fig. 5. Visual trend profiles of the five piperazines.

steady throughout the second generation. Akin to the AMT substance for the tryptamines class, the observed higher popularity could be due to alternative acronyms.

\subsubsection{Phencyclidine-type substances}

Fig. 7 represents the visual trend profiles of the three phencyclidine-type substances studied in this article.

MXE was the first substance to show popularity. As its activity dropped, 4-MEO-PCP experienced a peak in popularity in 2010. As soon as 4-MEO-PCP dropped in search numbers, MXE became popular again in parallel with 3-MEO-PCP. Subsequently, the decline of MXE searches matched a renewed interest in 3-MEO-PCP. A previous study showed that 4-MEO-PCP and 3-MEO-PCP are derivatives of MXE, which experienced increased activity on forums in 2009 with marked increases in 2011 [54].

\subsubsection{Synthetic cannabinoids}

Fig. 8 represents the visual trend profiles of the eleven synthetic cannabinoids studied in this article.

The synthetic cannabinoids class seemed to follow a generational trend. HU-210 was the first generation substance in this dataset. The JWH family (JWH-018, JWH-073, and JWH-250) revealed a clear subsequent block trend, which might have impacted the HU-210 trend. Then, the AM family (represented by AM-2233) showed a short period of activity. The PINACA family started at the end of 2012, followed by the CHMI family (AB-CHMINACA, ADB-CHMINACA,
MDMB-CHMICA) and finally leading to the 5F-MDMB-PINACA rise in 2015.

The evolution of the different generations observed through the data aligns accurately with observations in previous studies; the trend followed the synthesis and development of the different families of substances. HU-210 is the original component which led to the development of the JWH and AM groups [55-57]. The development of synthetic cannabinoids with greater structural diversity, that is the CHMICA, CHMINACA, and PINACA groups was also noted by the UNODC and other studies as the most recent waves of substances in this class [55-57]. The global increase of interest noted since 2008 might be due to their media coverage as legal alternative to cannabis [58].

\subsubsection{Synthetic cathinones}

Fig. 9 represents the visual trend profiles of the five synthetic cathinones studied in this article.

MDPV and Mephedrone were the first detected and probably the most consumed substances in this class as there are known to be the 'first generation' synthetic cathinones [59]. Mephedrone and 3-FMC experience a block trend pattern with a simultaneous increase and decrease of popularity. A successive trend pattern was then observed with a-PVP, a 'second generation' synthetic cathinone that entered the NPS market in response to the regulation of previously popular substances, such as MDPV [59,60]. This information is echoed in the Google Trends data, wherein a-PVP appeared in the second wave of substance popularity and could also explain why MDPV experienced 


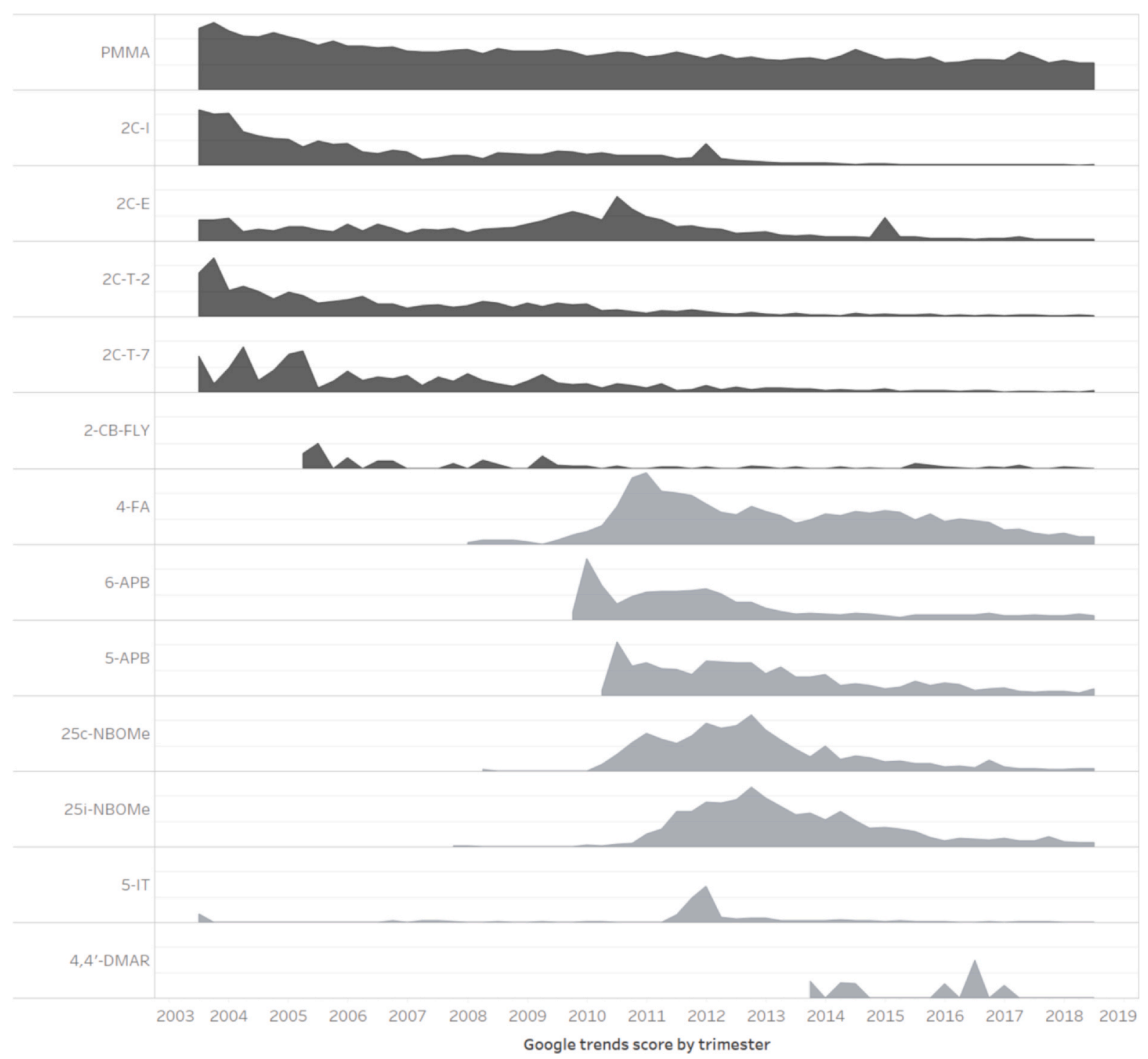

Fig. 6. Visual trend profiles of the thirteen phenethylamines (the change in colour represents the different generations of phenethylamines).

a peak in search frequency around this same period. N-ethyl-pentylone is recognized as one of the most recent NPS to emerge onto the market [61]. It is probably too early to interpret its temporal pattern, which still seems to be quite chaotic.

\subsubsection{Aminoindanes}

Fig. 10 represents the visual trend profiles of the three aminoindanes studied in this article.
Despite its low popularity globally, the aminoindanes group revealed one clear block trend for 5-IAI and MDAI. Indeed, they experienced a concomitant sharp popularity peak, followed by a continuous decrease. If 2-AI appears to have a continuous popularity, the popularity of all three substances seems to have decreased steadily since 2011. A literature review identified 2-IAI as the original analogue of amphetamine, followed by a number of derivatives such as MDAI and 5-IAI [42].

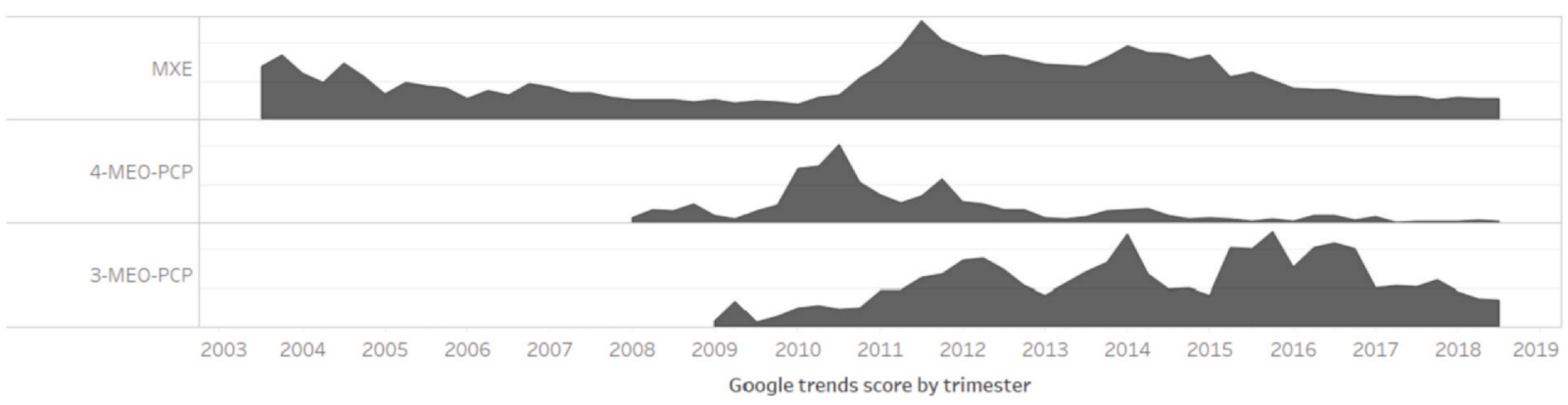

Fig. 7. Visual trend profiles of the three phencyclidine-type substances. 


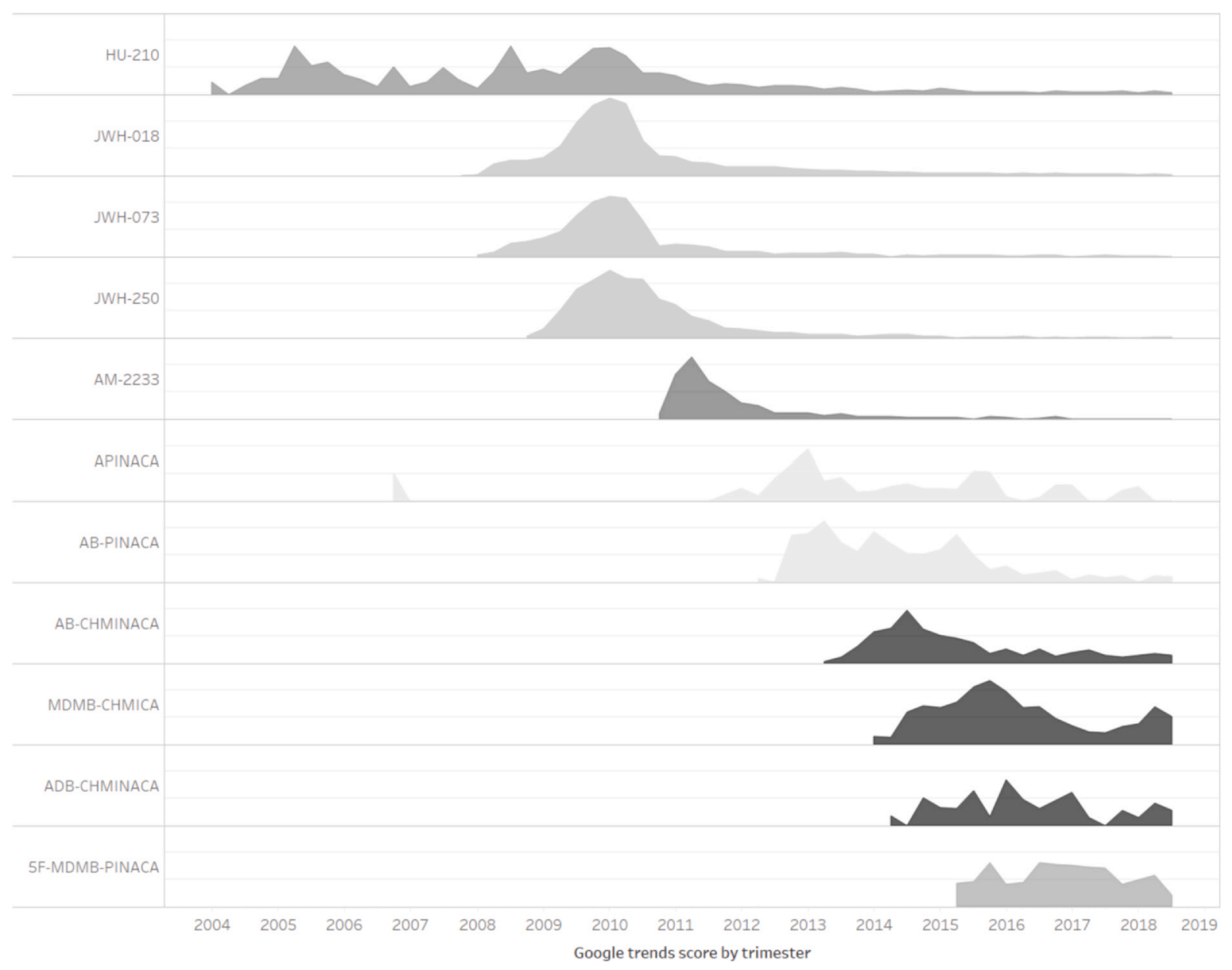

Fig. 8. Visual trend profiles of the eleven synthetic cannabinoids (the change in colour represents the different generations of synthetic cannabinoids).

\subsection{Added value of Google Trends as a monitoring tool}

Globally, Google Trends analysis revealed its ability to follow search activities for specific substances. Absence of searches, emerging interest, decrease of search activities, specific and chronic behaviours are the main trends detected while analysing Google Trends data. It has to be noted here that no periodical trends were presented, because no clear seasonal or cyclical trends were observed in the data. Indeed, more often than not, search activities do not vary significantly during weeks or months of the year, neither during days of the week. Observed trends allowed sorting substances in regard to the global online search behaviours. Since no analysis was performed for particular regions of the world, geographical analysis may be conducted in future research to better understand regional trends.

Results showed that Google Trends data can be used to follow temporal trends in popularity within classes (i.e. groups of substances). However, a complete analysis still requires to extend the

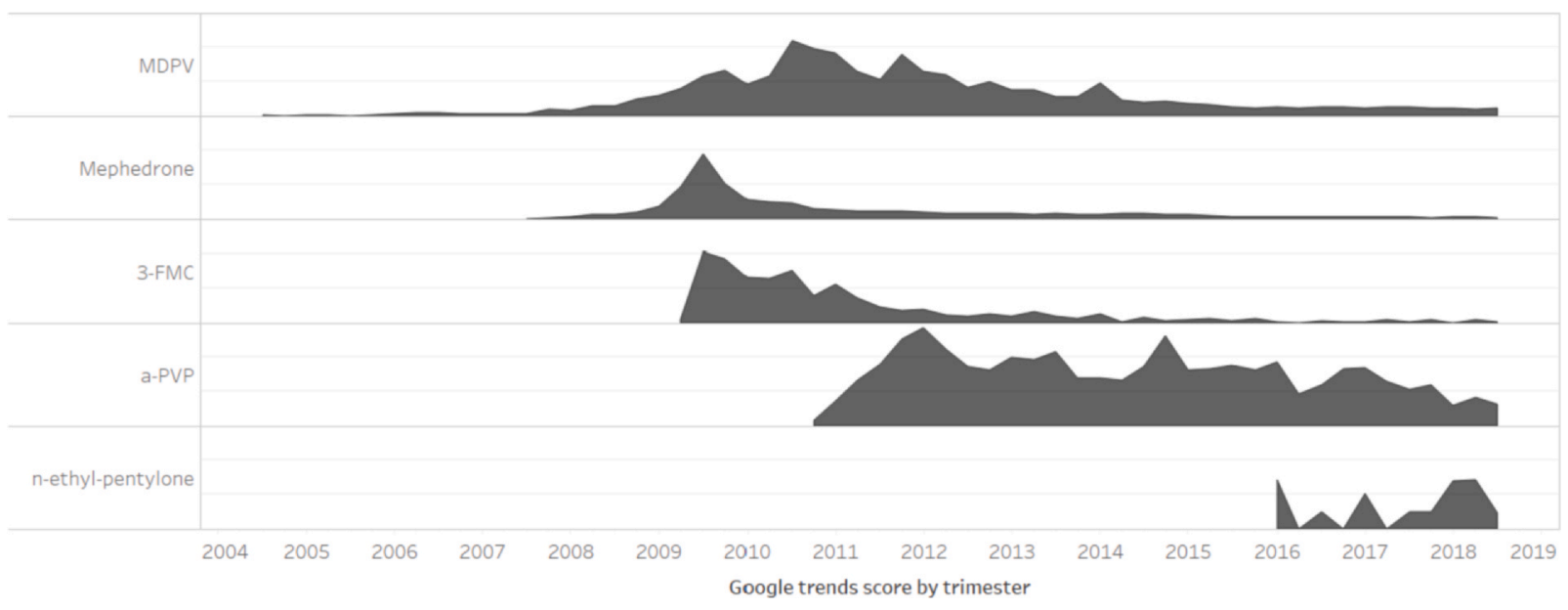

Fig. 9. Visual trend profiles of the five synthetic cathinones. 


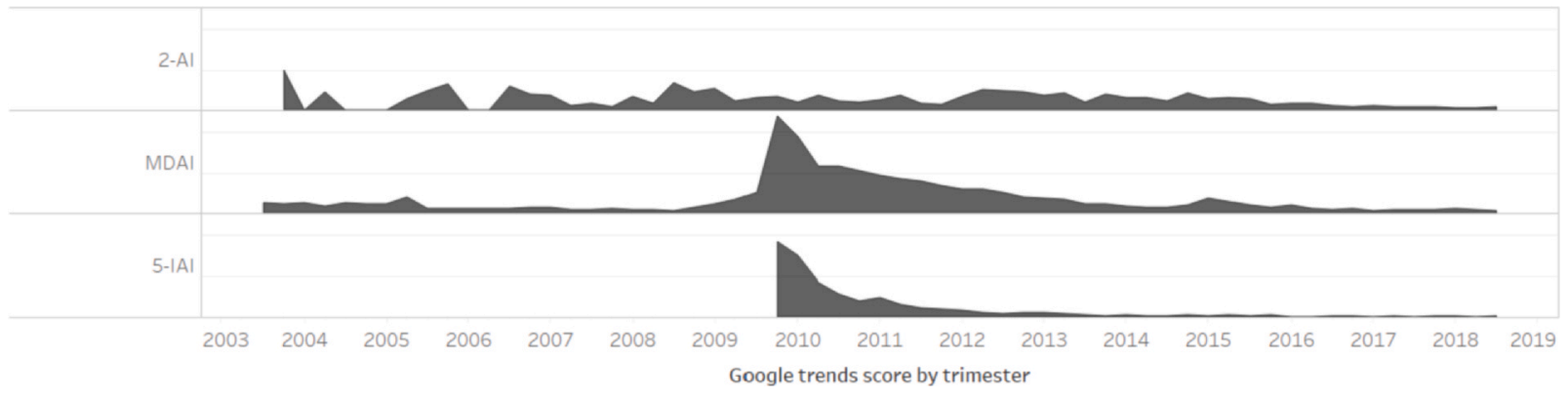

Fig. 10. Visual trend profiles of the three aminoindanes.

monitoring process to a more complete list of known substances. Despite this limitation, discernible trends were observed amongst the eight different classes of NPS, with either successive, block, or generation style trends. The detected trends have been linked to the known evolutions of NPS trends described in previous studies using other indicators [42-63]. For example, in the synthetic cannabinoids class, the Google Trends data exhibits the same evolution than the known evolution from HU-210 to the JWH and AM groups, followed by the most recent and more structurally diverse groups. Detected anomalies or peaks were also coherent with previous studies, such as the peak for MDAI and 5-IAI in the aminoindanes class. More often than not, observations made followed what would be expected to see based on the NPS cycle of production-consumption-regulation, where producers adapt to scheduling and move onto new substances. Typically, in the PCP-type category, MXE showed sustained popularity for some time but disappeared when 3-MEO-PCP and 4-MEO-PCP began to show increased interest. 4-MEO-PCP was not present for a long period of time. Its popularity dropped while 3MEO-PCP and MXE showed sustained popularity.

Moreover, some observation might be linked to legislative changes. For instance, New Zealand criminalised the sale and possession of BZP in 2008 (sale was immediately prohibited and, after a 6 -month amnesty period, possession of BZP became an offence) $[45,64]$. The drop in popularity and use can be observed in the continuous decrease in search value for the term 'BZP' on Google from 2008 onwards (see Fig. 5). Indeed, the drop in production would have led to a drop in popularity Worldwide as the resource became scarcer and other similar substances rose in availability. When comparing the Worldwide search to the New Zealand only search, there is a drop in 2008 in both trends data. Similarly, the regulation of MDPV in 2011-2013 in the United States [65-67] can be aligned with a decrease in search activity, overtaken by the development and rise in popularity of a-PVP in the synthetic cathinone market (not regulated until 2017) [66,67].

In comparison to the monitoring of drug discussion forums, Google Trends have the advantage of reporting on a regular timescale and do not require complex crawling and scraping methods. In addition, it is possible to collect weekly reports as well as monthly reports from Google Trends. However, monitoring forums allows to detect conversation related to substances, which might lead to qualitative studies and evaluations of the positive or negative perceptions about them. With Google Trends data, there is no method of ascertaining what the true intention of each search was.

\subsection{Limitations of Google Trends data}

Like any indicators, Google Trends data has its limitations. One of the major limitation of Google Trends data is the impossibility to ascertain whether the intention of a google search was about a particular NPS. For example, some substances like PMMA in the phenethylamines category and AMT in the tryptamines class are more difficult to monitor with Google Trends data. Whilst they may have a high popularity over the 15 -year period, the observed chronic trends are more likely due to their names being similar to other acronyms. For example, a search for 'PMMA' may have been intended for the NPS, or for a completely different entity such as 'Philippine Merchant Marine Academy' or 'Poly(methyl methacrylate)', but there is no way to look at the context of the searches that have contributed to the data provided. Moreover, the number of queries has to reach an unknown threshold to be reported by Google Trends.

Another limitation of this research is the frequency and precision of data reporting. Drugs-forum is publicly available in real-time, and as such 'web-crawling' systems can be implemented to extract data and produce on-command reports of forum activity. Google Trends is also publicly available in almost real-time and can easily be accessed to produce weekly or monthly activity reports, based on the time-range entered. As such, Drugs-Forum and Google Trends can be compared quite accurately as they both operate on similar timeframes. The UNODC however, only records the year in which a substance is first reported to the EWA. As a result, it is difficult to directly compare the UNODC report date to the higher frequency reporting of Drugs-Forum or Google Trends. One must consider where the UNODC date will be standardised when compared to the other two sources - beginning, middle, or end of year. Secondly, regardless of standardisation, any time differences and disparities between popularity of a substance and UNODC report date cannot be considered $100 \%$ accurate due to the large difference in reporting precision.

In addition, given the large number of NPS and the complexity of the terminology of many of them, google trends data may become limited as users or the general public may not know the actual names. This research focused on well known NPS and as a consequence, the benefit of the approach described in this paper should be further developed for less known NPS. An advantage of drug discussion forums is that the accuracy of the data is backed up by the ability to read the conversations that are the basis of the data being used; that is, one can always go back to the thread extracted and determine what the original posters true intention was.

\section{Conclusions}

The current NPS monitoring systems may have some difficulties to track changes in the market of NPS. In addition, the requirement of risk assessments means there is an even longer wait before the substance can be formally controlled. The evaluation of actual threats is thus complicated. This study evaluated the potential of using online public data from one forum (Drugs-Forum.com) and Google Trends as indirect proxies of the popularity of selected substances. Google Trends data from 2004 to 2019 for 48 popular NPS and their occurrences in threads on the Drugs-Forum (from 2003 to 2018) were compared with UNODC reports dates.

According to our findings, substances were most likely to appear on Google Trends first over the other two sources. This research 
allowed us to identify evident succession of substance popularity within classes. Between Google Trends and Drugs-Forum, six of eight classes showed remarkable similarity in substance succession. Substances were more likely to appear on Google Trends first and Google Trends also had a shorter median lag time in appearance of substances compared to Drugs-Forum. The two sources showed significant similarity in their visual trend profiles, with either peaks or falls in popularity aligning or periods of intense discussion centring around the same time. For Google Trends data only, three major trend types were observed (successive, block, and generational), with some classes exhibiting two trend types. Additionally, six subgroups identified in four classes showed similar trend profiles.

By combining these two data sources, it was possible to compare them and identify whether substances are increasing or decreasing in popularity in regard to search frequency on The Web. Whilst drug forums may be difficult and time-intensive to study based on the sheer amount of activity that must be analysed, this can be overcome by setting up an automatic web-crawling system. The Web, in particular drug forums, is a source of information for both potential drug consumers and experienced users $[4,15,18,68]$. The appearance of new compounds drives interested individuals to visit drug forums to seek harm-reducing information $[2,11,69]$. Hidden by the legal and social security provided by anonymity, NPS users will openly share their personal experiences, both positive and negative effects, with others on publicly available drug forums $[4,8,13,15,18]$. Experienced NPS users, referred to as 'e-Psychonauts', are known to contribute high quality knowledge to drug forums [11,15]. In addition, given that the conversations about substances are available, it is possible to understand the reasons why people are discussing these substances. Google information, however, is quicker and easier to analyse as one simply needs to input the term into the engine to retrieve data. Additionally, substances were more likely to appear on Google Trends first. Nevertheless, to use Google Trends, one needs to know what to look for and a minimum threshold of searches is required to provide data, which could prove difficult when trying to detect new substances as in the early stages of drug circulation.

Google Trends could be used to complement current monitoring system, such as EWA or EWS. As Google Trends can monitor substances in a 'real-time' setting, this could decrease the time required before pre-monitoring for a risk assessment can begin, as the reliance is no longer on the first report but rather the increased interest online. Google Trends showed the emergence, persistence, or transient nature of substances. This finding is interesting as it could, in combination to current monitoring systems, help direct the focus of law enforcement and health organisations resources and research towards a limited number of substances rather than all new substances. Harm reduction initiatives such as prevention campaigns could also benefit from this knowledge (e.g. addiction problems discussed on the forums). As a result, Google Trends could be used as a complement to current early warning systems. It would also be excellent for forward-casting when looking at the effects of legislative responses, particularly with the synthetic cannabinoids.

As new substances begin to appear on the NPS market, the difference in when a source first began $(2002,2004$, or 2009) will not pose further limitations for use of this monitoring system. However, the frequency and precision of reporting will remain an important factor in the provision of high-quality data, as accurately comparing sources which report with high frequency to sources which report by year only will remain difficult.

As only one online discussion forum was utilised in this research, future work should attempt to include data extracted from a number of popular drug forums to identify whether popularity trends show similarity between the different discussion platforms and to strengthen the available data. Additionally, a text-mining tool could be developed to help identify particular terms that may appear when a discussion is triggered on drug forums.
This work categorises the substances based on their chemical structures while the UNODC also uses an effect-based classification. As people who use drugs do it primarily for a specific desired effect, it would be of interest to compare the results obtained in this study with results obtained using an effect-based classification as the latter classification could lead to a better understanding of the dynamics and popularity of substances.

As this research targeted mainly well-known substances, future work should trial newer substances. This would allow us to ultimately determine the strength of this system for future monitoring purposes as well as the feasibility of the system for early action.

Finally, as any market indicator, Google Trends has its limitation and should be used in combination with traditional monitoring systems.

\section{Funding}

This research did not receive any specific grant from funding agencies in the public, commercial, or not-for-profit sectors.

\section{CRediT authorship contribution statement}

Frana-Katica Batistic: Data curation, Formal analysis, Writing original draft. Damien Rhumorbarbe: Conceptualization, Supervision, Methodology, Writing - review \& editing. Elodie Lefrancois: Supervision, Methodology, Writing - review \& editing. Justice Tettey: UNODC data provision, Writing - review \& editing. Martin Raithelhuber: UNODC data provision, Writing - review \& editing. Quentin Rossy: Data curation, Visualization, Writing - review \& editing. Marie Morelato: Conceptualization, Supervision, Methodology, Writing - original draft.

\section{Conflict of interest}

The authors declare no conflict of interest.

\section{References}

[1] D. Baumeister, L.M. Tojo, D.K. Tracy, Legal highs: staying on top of the flood of novel psychoactive substances, Ther. Adv. Psychopharmacol. 5 (2015) 97-132.

[2] O.R. Bilgrei, From "herbal highs" to the "heroin of cannabis": exploring the evolving discourse on synthetic cannabinoid use in a norwegian internet drug forum, Int. J. Drug Policy 29 (2016) 1-8.

[3] L. Burns, A. Roxburgh, R. Bruno, J. Van Buskirk, Monitoring drug markets in the internet age and the evolution of drug monitoring systems in australia, Drug Test. Anal. 6 (2014) 840-845.

[4] European Monitoring Centre for Drugs and Drug Addiction and Europol, Eu Drug Markets Report: In-Depth Analysis, Publications Office of the European Union, Luxembourg, 2016.

[5] G.R. Potter, C. Chatwin, Not particularly special: Critiquing 'nps' as a category of drugs, Drug.: Educ. Prev. Policy 25 (2018) 329-336.

[6] K. O'Brien, C. Chatwin, C. Jenkins, F. Measham, New psychoactive substances and british drug policy: a view from the cyber-psychonauts, Drug.: Educ. Prev. Policy 22 (2015) 217-223.

[7] M.H. Baumann, R.A. Glennon, J.L. Wiley (Eds.), Neuropharmacology of New Psychoactive Substances (NPS): The Science Behind the Headlines, Springer International Publishing, United States, 2017.

[8] E. Deligianni, J.M. Corkery, F. Schifano, L.A. Lione, An international survey on the awareness, use, preference, and health perception of novel psychoactive substances (NPS), Hum. Psychopharmacol.: Clin. Exp. 32 (2017) e2581.

[9] European Monitoring Centre for Drugs and Drug Addiction (2018), European drug report: Trends and developments, Lisbon, Portugal.

[10] R. Bruno, R. Poesiat, A.J. Matthews, Monitoring the internet for emerging psychoactive substances available to australia, Drug Alcohol Rev. 32 (2013) 541-544.

[11] Z. Davey, F. Schifano, O. Corazza, P. Deluca, E-psychonauts: Conducting research in online drug forum communities, J. Ment. Health 21 (2012) 386-394.

[12] P. Deluca, Z. Davey, O. Corazza, L. Di Furia, M. Farre, L.H. Flesland, M. Mannonen, A. Majava, T. Peltoniemi, M. Pasinetti, C. Pezzolesi, N. Scherbaum, H. Siemann, A. Skutle, M. Torrens, P. van der Kreeft, E. Iversen, F. Schifano, Identifying emerging trends in recreational drug use; outcomes from the psychonaut web mapping project, Prog. Neuro-Psychopharmacol. Biol. Psychiatry 39 (2012) 221-226.

[13] L.A. King, A.T. Kicman, A brief history of 'new psychoactive substances', Drug Test. Anal. 3 (2011) 401-403. 
[14] V. Patil, A. Tewari, R. Rao, New psychoactive substances: issues and challenges, J. Ment. Health Hum. Behav. 21 (2016) 98-104.

[15] C. Soussan, A. Kjellgren, Harm reduction and knowledge exchange-a qualitative analysis of drug-related internet discussion forums, Harm Reduct. J. 11 (2014) 25.

[16] United Nations Office for Drugs and Crime, Early Warning Advisory on New Psychoactive Substances - What is the Early Warning Advisory? 2019.

[17] European Monitoring Centre for Drugs and Drug Addiction, Emcdda-Europol 2010 Annual Report on the Implementation of Council Decision 2005/387/jha, Lisbon, Portugal, 2011.

[18] M.M. Young, C. Dubeau, O. Corazza, Detecting a signal in the noise: monitoring the global spread of novel psychoactive substances using media and other opensource information, Hum. Psychopharmacol.: Clin. Exp. 30 (2015) 319-326.

[19] D. Korf, A. Benschop, B. Werse, G. Kamphausen, K. Felvinczi, K. Dąbrowska, S. Hernriques, T. Nabben, Ł. Wieczorek, M. Bujalski, Z. Kalo, E. Hearne, M.C. Van Hout, How and where to find nps users: a comparison of methods in a crossnational survey among three groups of current users of new psychoactive substances in europe, Int. J. Ment. Health Addict. (2019) 1-18.

[20] D. Rhumorbarbe, M. Morelato, L. Staehli, C. Roux, D.-O. Jaquet-Chiffelle, Q. Rossy, P. Esseiva, Monitoring new psychoactive substances: exploring the contribution of an online discussion forum, Int. J. Drug Policy 73 (2019) 273-280.

[21] T. Pineau, A. Schopfer, L. Grossrieder, J. Broséus, P. Esseiva, Q. Rossy, The study of doping market: how to produce intelligence from internet forums, Forensic Sci. Int. 268 (2016) 103-115.

[22] S. Vosen, T. Schmidt, Forecasting private consumption: survey-based indicators vs. Google trends, J. Forecast. 30 (2011) 565-578.

[23] A. Al-Imam, B.A. AbdulMajeed, Captagon, octodrine, and nbome: an integrative analysis of trends databases, the deep web, and the darknet, Glob. J. Health Sci. 9 (2017) 114-125.

[24] M. Blankers, D. van der Gouwe, M. van Laar, 4-fluoramphetamine in the netherlands: text-mining and sentiment analysis of internet forums, Int. J. Drug Policy 64 (2019) 34-39.

[25] V. Catalani, M. Prilutskaya, A. Al-Imam, S. Marrinan, Y. Elgharably, M. Zloh, G. Martinotti, R. Chilcott, O. Corazza, Octodrine: new questions and challenges in sport supplements, Brain Sci. 8 (2018) 34.

[26] A. Gamma, R. Schleifer, W. Weinmann, A. Buadze, M. Liebrenz, Could google trends be used to predict methamphetamine-related crime? An analysis of search volume data in switzerland, germany, and austria, PLOS ONE 11 (2016) 0166566.

[27] M. Chary, D. Yi, A.F. Manini, Candyflipping and other combinations: identifying drug-drug combinations from an online forum, Front. Psychiatry 9 (2018) 135.

[28] S.J. Bright, B. Bishop, R. Kane, A. Marsh, M.J. Barratt, Kronic hysteria: exploring the intersection between australian synthetic cannabis legislation, the media, and drug-related harm, Int. J. Drug Policy 24 (2013) 231-237.

[29] A. Al-Imam, B.A. AbdulMajeed, The most popular chemical categories of nps in four leading countries of the developed world: an integrative analysis of trends databases, surface web, and the deep web, Glob. J. Health Sci. 9 (2017) 27-39.

[30] A. Al-Imam, B.A. AbdulMajeed, The nps phenomenon and the deep web: Internet snapshots of the darknet and potentials of data mining, Glob. J. Health Sci. 9 (2017) 86-101.

[31] A. Al-Imam, B.A. AbdulMajeed, The nps phenomenon and the deep web: trends analyses and internet snapshots, Glob. J. Health Sci. 9 (2017) 71-85.

[32] A. Al-Imam, Retrospective analyses of high-risk nps: integrative analyses of pubmed, drug fora, and the surface web, Glob. J. Health Sci. 9 (2017) 40-50.

[33] United Nations Office for Drugs and Crime, Nps Substance Groups. 2019.

[34] J.N.A. Tettey, C. Crean, S.C. Ifeagwu, M. Raithelhuber, Emergence, diversity, and control of new psychoactive substances: A global perspective, in: H.H. Maurer, S.D. Brandt (Eds.), New psychoactive substances: Pharmacology, clinical, forensic and analytical toxicology, Springer International Publishing, United States, 2018, pp. 51-67.

[35] H. Choi, H. Varian, Predicting the present with google trends, Econ. Rec. 88 (2012) 2-9.

[36] Google Trends Help, Google Trends Help, 2019, vol. 2019.

[37] A. Seifter, A. Schwarzwalder, K. Geis, J. Aucott, The utility of "google trends" for epidemiological research: Lyme disease as an example, Geospatial Health 4 (2010) 135-137.

[38] M.C. Van Hout, E. Hearne, New psychoactive substances (nps) on cryptomarket fora: an exploratory study of characteristics of forum activity between nps buyers and vendors, Int. J. Drug Policy 40 (2017) 102-110.

[39] United Nations Office on Drugs and Crime, The Global Smart Programme: A Strategic Response to the Synthetic Drug Problem, Vienna, Austria, 2014.

[40] UNODC Early Warning Advisory on New Psychoactive Substances, February 2019 UNODC-SMART: Almost 900 nps Reported to UNODC from 119 Countries and Territories, 2019.

[41] M.S. Castaneto, D.A. Gorelick, N.A. Desrosiers, R.L. Hartman, S. Pirard, M.A. Huestis, Synthetic cannabinoids: epidemiology, pharmacodynamics, and clinical implications, Drug Alcohol Depend. 144 (2014) 12-41.
[42] P.D. Sainsbury, A.T. Kicman, R.P. Archer, L.A. King, R.A. Braithwaite, Aminoindanes-the next wave of 'legal highs'? Drug Test. Anal. 3 (2011) $479-482$.

[43] S. Elliott, Current awareness of piperazines: pharmacology and toxicology, Drug Test. Anal. 3 (2011) 430-438.

[44] D. Zuba, B. Byrska, Prevalence and co-existence of active components of 'legal highs', Drug Test. Anal. 5 (2013) 420-429.

[45] J. Sheridan, C.Y. Dong, R. Butler, J. Barnes, The impact of new zealand's 2008 prohibition of piperazine-based party pills on young people's substance use: results of a longitudinal, web-based study, Int. J. Drug Policy 24 (2013) 412-422.

[46] R. Sutherland, A. Peacock, E. Whittaker, A. Roxburgh, S. Lenton, A. Matthews, K. Butler, M. Nelson, L. Burns, R. Bruno, New psychoactive substance use among regular psychostimulant users in australia, 2010-2015, Drug Alcohol Depend. 161 (2016) 110-118.

[47] US Department of Justice Drug Enforcement Administration, National Forensic Laboratory Information System Special Report: Emerging 2C-phenethylamines, Piperazines, and Tryptamines in NFLIS, 2006-2011, 2012.

[48] U. Antia, M.D. Tingle, B.R. Russell, 'Party pill' drugs-bzp and tfmpp, J. N. Z. Med. Assoc. 122 (2009) 55-68.

[49] D. de Boer, I. Bosman, A new trend in drugs-of-abuse; the 2c-series of phenethylamine designer drugs, Pharm. World Sci. 26 (2004) 110-113.

[50] L.A. King, New phenethylamines in europe, Drug Test. Anal. 6 (2014) 808-818.

[51] United Nations Office for Drugs and Crime, Phenethylamines, 2019.

[52] J.B. Zawilska, D. Andrzejczak, Next generation of novel psychoactive substances on the horizon - a complex problem to face, Drug Alcohol Depend. 157 (2015) $1-17$.

[53] S.D. Brandt, L.A. King, M. Evans-Brown, The new drug phenomenon, Drug Test. Anal. 6 (2014) 587-597.

[54] M. Bäckberg, O. Beck, A. Helander, Phencyclidine analog use in sweden-intoxication cases involving 3-meo-pcp and 4-meo-pcp from the strida project, Clin. Toxicol. 53 (2015) 856-864.

[55] L. Fattore, W. Fratta, Beyond thc: The new generation of cannabinoid designer drugs, Front. Behav. Neurosci. 5 (2011) 60 60-60.

[56] United Nations office for Drugs and Crime, Synthetic Cannabinoids, 2019.

[57] M. Wilson-Hohler, W. Fathy, A. Mozayani, How present synthetic cannabinoids can help predict symptoms in the future, MOJ Toxicol. (2016) 18-24.

[58] United Nations Office for Drugs and Crime, Synthetic Cannabinoids in Herbal Products, 2010.

[59] L.R. Watterson, M.F. Olive, Synthetic cathinones and their rewarding and reinforcing effects in rodents, Adv. Neurosci. 2014 (2014) 209875.

[60] M. Katselou, I. Papoutsis, P. Nikolaou, C. Spiliopoulou, S. Athanaselis, A-pvp ("flakka"): a new synthetic cathinone invades the drug arena, Forensic Toxicol. 34 (2016) 41-50.

[61] A.J. Krotulski, D.M. Papsun, B.S. De Martinis, A.L.A. Mohr, B.K. Logan, N-ethyl pentylone (ephylone) intoxications: quantitative confirmation and metabolite identification in authentic human biological specimens, J. Anal. Toxicol. 42 (2018) 467-475.

[62] A.M. Araújo, F. Carvalho, M. d L. Bastos, P. Guedes de Pinho, M. Carvalho, The hallucinogenic world of tryptamines: an updated review, Arch. Toxicol. 89 (2015) 1151-1173.

[63] Á.J. Palma-Conesa, M. Ventura, L. Galindo, F. Fonseca, M. Grifell, P. Quintana, I. Fornís, C. Gil, M. Farré, M. Torrens, Something new about something old: a 10year follow-up on classical and new psychoactive tryptamines and results of analysis, J. Psychoact. Drugs 49 (2017) 297-305.

[64] J.R. Kerr, L.S. Davis, Benzylpiperazine in new zealand: brief history and current implications, J. R. Soc. N. Z. 41 (2011) 155-164.

[65] M.H. Baumann, M.O. Bukhari, K.R. Lehner, S. Anizan, K.C. Rice, M. Concheiro, M.A. Huestis, Neuropharmacology of 3,4-methylenedioxypyrovalerone (mdpv), its metabolites, and related analogs, in: M.H. Baumann, R.A. Glennon, J.L. Wiley (Eds.), Neuropharmacology of New Psychoactive Substances (NPS): The Science Behind the Headlines, Springer International Publishing, United States, 2017, pp. 93-117.

[66] K.R. Bonson, T. Dalton, D. Chiapperino, Scheduling synthetic cathinone substances under the controlled substances act, Psychopharmacology 236 (2019) $845-860$.

[67] J. Fratantonio, L. Andrade, M. Febo, Designer drugs: a synthetic catastrophe, J. Reward Defic. Syndr. 1 (2015) 82-86.

[68] J.G.C. van Amsterdam, T. Nabben, D. Keiman, G. Haanschoten, D. Korf, Exploring the attractiveness of new psychoactive substances (nps) among experienced drug users, J. Psychoact. Drugs 47 (2015) 177-181.

[69] B. Tighe, M. Dunn, F.H. McKay, T. Piatkowski, Information sought, information shared: exploring performance and image enhancing drug user-facilitated harm reduction information in online forums, Harm Reduct. J. 14 (2017) 48. 